\begin{abstract}
Наведено спосіб визначення нехаотичних траєкторій коливання вантажів консервативних маятникових систем за допомогою графічної технологї проекційного фокусування. При цьому фазові траєкторії диференціальних рівнянь коливань Лагранжа другого роду розглядаються як проекиії інтегральних кривих з фазового простору на фазову площину. Наведено приклади обчислення нехаотичних траєкторій деяких маятникових систем

Ключові слова: маятникові системи, консервативні системи, інтегральні криві, фазові траєкторії, проекційне фокусування
\end{abstract}

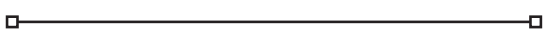

Приведен способ определения нехаотических траекторий колебания грузов консервативных маятниковых систем при помощи графической технологии проекционного фокусирования. При этом фазовые траектории дифференциальных уравнений колебаний Лагранжа второго рода рассматриваются как проекции интегральных кривых из фазового пространства на фазовую плоскость. Приведены примеры вычисления нехаотических траекторий некоторых маятниковых систем

Ключевые слова: маятниковые системы, консервативные системы, интегральные кривые, фазовые траектории, проекционное фокусирование

\section{$\square \quad$}

UDC 514.18053.81+004.91

DOI: $10.15587 / 1729-4061.2017 .95764$

DEVELOPMENT OF

PROJECTION TECHNIQUE FOR DETERMINING THE NON-CHAOTIC OSCILLATION TRAJECTORIES IN THE CONSERVATIVE PENDULUM SYSTEMS

O. Se m kiv

$\mathrm{PhD}$, Vice-Rector

National University of Civil Defense of Ukraine Chernyshevska str., 94, Kharkiv, Ukraine, 61023

E-mail: legooleg1@rambler.ru

O. S hom a n

Doctor of Technical Sciences, Professor, Head of Department* E-mail: olgasho@ukr.net E. S u k hark ova Assistant

Department of Descriptive Geometry and Computer Graphics Ukrainian State University of Railway Transport Feierbakha sq., 7, Kharkiv, Ukraine, 61050

E-mail: lena_sukharkova@mail.ru

A. Zhurilo

$\mathrm{PhD}$, Associate Professor* E-mail: zhurilo.alla@ukr.net

H. Fed che n k o PhD, Associate Professor*

E-mail: anna-fedchenko@ukr.net *Department of Geometrical Modeling and Computer Graphics National Technical University "Kharkiv Polytechnic Institute" Kyrpychova str., 2, Kharkiv, Ukraine, 61002

\section{Introduction}

An experience in solving a number of applied problems demonstrates that a road to the result will be more efficient if one considers the "inner" projection nature of such problems. Sometimes, one manages to reduce a "parametric dimensionality" of problems by mapping a certain geometric object, stipulated by the problem statement, onto a coordinate hyper-plane in the same parameter space. In this case, computations, associated with the conversion of graphic information about the image representation, allow obtaining an effective solution for the original problem. Strict scientific explanation for this phenomenon is to be found in the mathematical theories, in particular, in the disaster theory [1].

In connection to this, there came an idea to create a graphic technology for calculating the pendulum mechanical oscillato- ry systems in order to provide for a non-chaotic (that is, such that satisfies a certain technology) character of the motion of their elements through a proper choice of parameters. The problem on calculating the dynamics of pendulum system is a traditional subject of research in theoretical mechanics, where the simplicity of setting a task is combined with the complexity of its solution [2]. The designs of pendulum mechanical systems are very different. Lengths of elements may periodically vary, suspension points can vibrate, and elastic elements may also be applied. At arbitrary values of parameters and initial conditions for the initiation of load motion, oscillations will be discovered in chaotic trajectories. The complexity of research into pendulum systems is explained by the need to take into account qualitatively different parameters - metric, angular, weight, as well as rigidity coefficients of the spring elements. That is why it is a relevant direction to develop and formalize a procedure for 
choosing the combination of parameters and initial conditions for the initiation of oscillations, which would provide for the technological trajectory of load in the implemention of specific designs of pendulum systems.

In order to solve this problem, we propose in this work to apply geometric apparatus for mapping onto the phase plane the integral curves of second order Lagrange differential equations that describe pendulum mechanical oscillations. The key provision of this idea is constructing a second order Lagrange differential equation, its integration with the required initial conditions and selection of the solution that would meet the necessary requirements to an oscillatory system [3]. We shall note that the very process of selecting parameters and initial conditions is the least examined in terms of its formalization [4].

In the present paper we consider those model problems in which oscillatory systems are conservative. In other words, here we tackle only those idealized systems in which the reserve of mechanical energy in the process of oscillations remains constant [5].

\section{Literature review and problem statement}

Effectively solving the initial problem can be realized by the computations associated with the conversion of graphic information about the image of mapping since the notion of mapping permeates many fields of natural sciences with a typical example being the disaster theory [1]. However, in the implementation of such an approach, techniques to map the objects are still insufficiently developed, for example, in descriptive geometry. At the intuitive-applied level, mapping is defined by the rule (algorithm), by which each element from some assigned set is matched with a certain element of another assigned set. A "projection" character of relation between the surface of equilibrium and bifurcation set in the disaster theory stimulated the search for similar situations by the means of graphical computer technologies.

It is advisable to include into the set of projection methods a technique for analysis of oscillations at the qualitative level [5], where graphic information (integral curves and phase trajectories) has not been used to a proper degree, which is characteristic for this class of problems. In a general case, the following three stages of solution are typically considered: determining the specific points that match the equilibrium states of an oscillatory system, construction of phase portraits of the system with the controlling parameter values within the range of special points, as well as finding the separatrices, which run through special points, by using the integral equation of system energy when the kinetic energy equals zero [6]. By this information, not sufficiently formalized for the construction of algorithms [7], they usually determine the parameters and initial conditions, which would provide for the technological trajectories of pendulum oscillations [8]. But for practical implementations, it is necessary to employ an engineering technique for determining non-chaotic oscillations of pendulum systems. For example, a peculiarity for a significant number of pendulum systems is a movable point of suspension $[9,10]$, as well as a combined character of oscillations [11, 12]. And for all of these, as well as other variants of oscillatory systems, it is necessary to be able to determine the non-chaotic trajectories in the oscillations of their loads.

That is why, in practice, the artificial (engineering) means are used to find the non-chaotic trajectories. For example, a computation of initial angles for the double pendulum implies the following [13]:

1) the equation is built, where the left part is the expression of the system's initial energy at unknown initial angles of deviation; the right part are the numerical values of dimensionless starting energy;

2) by assigning the first angle, they solve the equation relative to the second angle;

3 ) the assigned first and the found second angles are fitted to the initial conditions of the system of differential equations of the system motion. This system of equations is solved and some phase portrait of the system is obtained;

4) by varying the angle values so that the closed lines are formed on the phase portrait, they receive the values of both angles that meet the original criteria for establishing the periodic mode of motion.

It is necessary to complete all the points in the algorithm, initially at a low value of starting energy, then, by assigning its increment, to conduct iterations with the subsequent values. The disadvantages in the method of article [13] include compulsory stages in the selection of parameters without visualizing the intermediate results that substantially increases complexity in the selection of variants.

Development of projection graphic computer technologies for examining the non-chaotic oscillations of pendulum systems is the subject of the present work. In our case, much attention is paid to the visualization of intermediate results in the computations.

\section{The aim and tasks of the study}

The aim of this work is to develop a method to study conditions for the existence of non-chaotic load oscillation trajectories in the pendulum mechanical conservative systems. This will make it possible to define the parameters for a certain pendulum mechanism, which would provide for the oscillation of its load along the non-chaotic trajectory.

To achieve the set aim, the following tasks are to be solved:

- to propose a notion of the focus-line of parametric family of curves and a technique for the projection focusing, which is based on this concept;

- to construct integral curves in the phase space based on the numerical solution of second order Lagrange differential equations, which describe the types in the oscillations of pendulum systems;

- to determine the critical value of pendulum oscillation parameter by using the graphic notion of projection focusing of phase trajectories in the solutions for second order Lagrange differential equations;

- to give examples of determining the parameters of some pendulum systems, which would provide for the non-chaotic oscillation trajectories of their loads.

\section{Materials and methods for examining the conditions of the existence of non-chaotic load oscillation trajectories in the pendulum mechanical conservative systems}

4. 1. Basic concepts in the mapping of projection focusing

Here are the basic concepts in the mapping of projection focusing [14]. 
Assume that a parametric family of lines L is assigned in the Cartesian coordinate system Oxy, which is described by equations:

$$
\mathrm{x}=\mathrm{x}(\mathrm{t}) ; \mathrm{y}=\mathrm{y}(\mathrm{t}) \text { or } \mathrm{F}(\mathrm{x}, \mathrm{y}, \mathrm{C})=0
$$

whose elements do not cross outside the rectangle:

$$
\mathrm{a}<\mathrm{x}<\mathrm{b} ; \mathrm{c}<\mathrm{y}<\mathrm{d}
$$

Here $\mathrm{C}$ is the parameter that controls a geometric shape of the family elements (i.e. a controlling parameter).

In order to explore the properties of family of lines $L$ that are used in practice, the means of differential computation are usually employed. A typical example is defining the envelope of family of lines $\mathrm{L}$ as one of the properties of a parametric family [15]. But geometric properties of the family of lines $\mathrm{L}$ have not been investigated yet, which are associated with determining the saturation (or density on the plane) of mapping the family of lines L. A property of saturation in the image of the family of lines $L$ is characterized by the number of conditional points in the Oxy plane (we shall denote them as "pixels") that make up the images built by the means of computer graphics [16]. It can be seen at the intuitive level that Fig. 1, $a$ shows a family of lines, which is more saturated with points than that in Fig. 1, $b$.

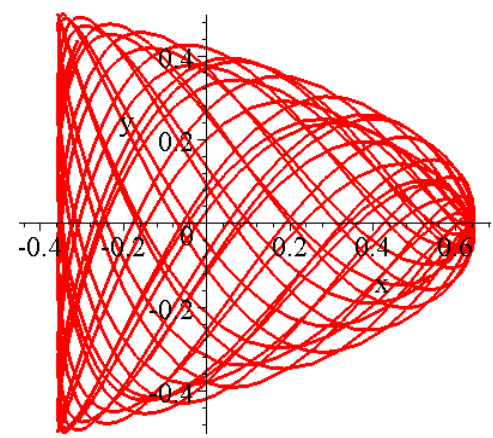

$a$

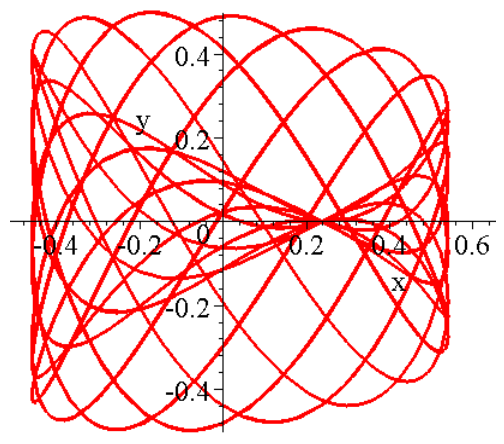

$b$

Fig. 1. Images of elements of a family of lines, which have different saturation: $a$ - larger saturation; $b$ - lower saturation

In order to formalize the notion of saturation, one should assume that the image of the family of lines $L$ is built on the computer monitor screen in the form of a discrete set of points, which in this case had been agreed to be denoted as pixels.

Then the measure of saturation is the number of pixels by which the family of lines L was visualized with accuracy acceptable for practice.
Thus, for the parametric family of lines, described by equations:

$$
\mathrm{x}=\mathrm{x}(\mathrm{t}) ; \mathrm{y}=\mathrm{y}(\mathrm{t}) \text { або } \mathrm{F}(\mathrm{x}, \mathrm{y}, \mathrm{C})=0,
$$

it is necessary to compute such a value of controlling parameter $\mathrm{C}$ (that changes within the range of $\mathrm{u}<\mathrm{C}<\mathrm{v}$ ) at which the saturation of the image of the family of lines is minimal. We shall denote the found value of the parameter as critical and designate $\mathrm{C}_{\mathrm{c}}$.

Definition. We shall denote as a focus-line that element $\mathrm{L}_{c}$ in the family of lines, which matches critical value of parameter $\mathrm{C}_{\mathrm{c}}$.

The term "focus-line" is chosen considering the fact that the process of search for the image of the family of lines with minimum saturation can be compared to the convolution, gathering in a heap, "image sharpening" - in other words, focusing.

Consider the family of lines, described by equations:

$x=\cos (2 C+t) \sin (t+C) ; y=0,5 \sin (3+t C) \cos (t-C)$,

where parameter $\mathrm{C}$ changes within $3.1<\mathrm{C}<3.9$.

Fig. 2 shows elements of the family of curves for some values of $\mathrm{C}$.

Fig. 2 on the left shows variants, among which one will probably be close to the critical value of parameter $\mathrm{C}$.

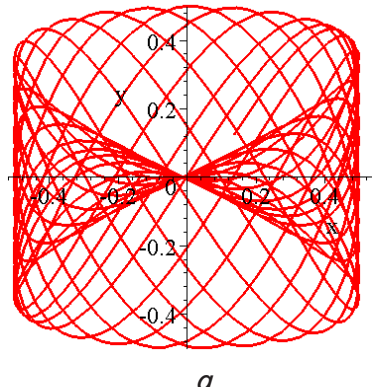

a

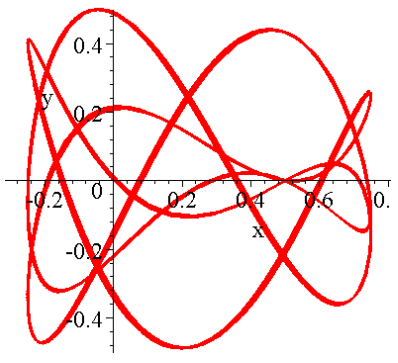

C

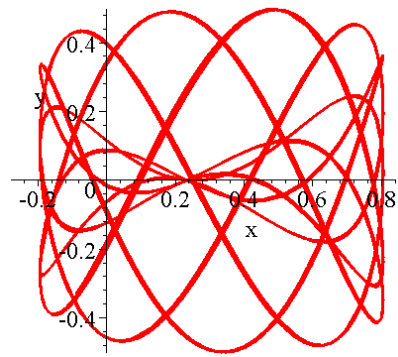

e

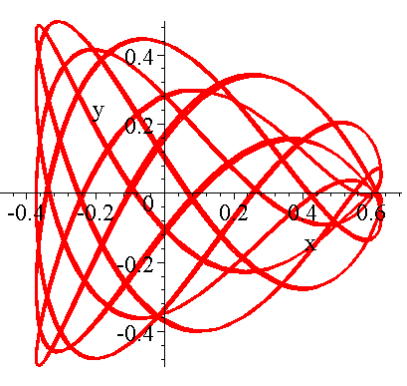

$b$

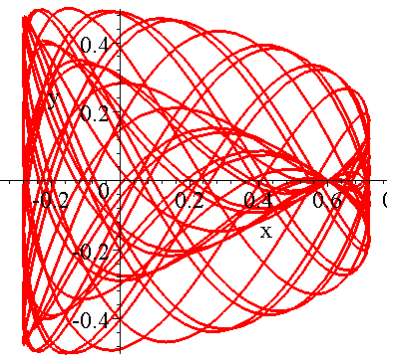

d

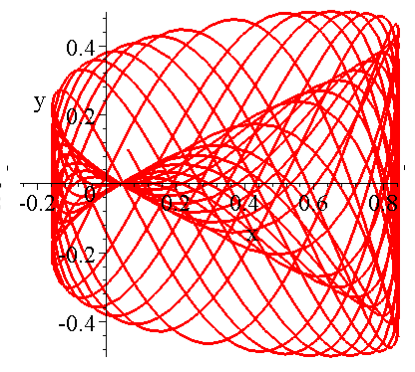

$f$
Fig. 2. Elements of family (1) dependent on parameter $C$ : $a-$ at $\mathrm{C}=3.12 ; b-$ at $\mathrm{C}=3.4 ; c-$ at $\mathrm{C}=3.6 ; d-$ at $\mathrm{C}=3,67$; $e-$ at $\mathrm{C}=3.8 ; f-$ at $\mathrm{C}=3.9$ 
In order to solve the assigned problem on computing the value of $C$, which will ensure minimum saturation in the image of family of lines, we built an universal algorithm.

The input parameters are:

- equation of parametric family of curves:

$\mathrm{x}=\mathrm{x}(\mathrm{t}) ; \mathrm{y}=\mathrm{y}(\mathrm{t})$

- a number of frames in animation $\mathrm{S}$;

- boundaries of change in the value of parameter $\mathrm{C}_{\mathrm{min}}$ and $\mathrm{C}_{\max }$;

- a number of points on curve $\mathrm{W}$;

- a number of pixels along vertical $\mathrm{N}$ and horizontal $\mathrm{M}$.

The variant was calculated at parameters $S=150$; $\mathrm{W}=1500 ; \mathrm{N}=\mathrm{M}=400$.

As a result, we constructed a graph of dependence of the number of points on the image of the family of lines on the values of parameter $\mathrm{C}$.

Fig. 3 shows a graph of dependence of the number of points on the image of the family of lines (1) on the values of parameter $\mathrm{C}$ (within the range from $\mathrm{C}_{\min }=3.1$ to $\mathrm{C}_{\max }=3.9$ ). A global minimum of the number of points $\mathrm{N}_{\mathrm{p}}=4896$ is achieved at value $\mathrm{C}=3.3986$.

Fig. 4 shows a family element (1) at critical value of parameter $\mathrm{C}=3.3986$.

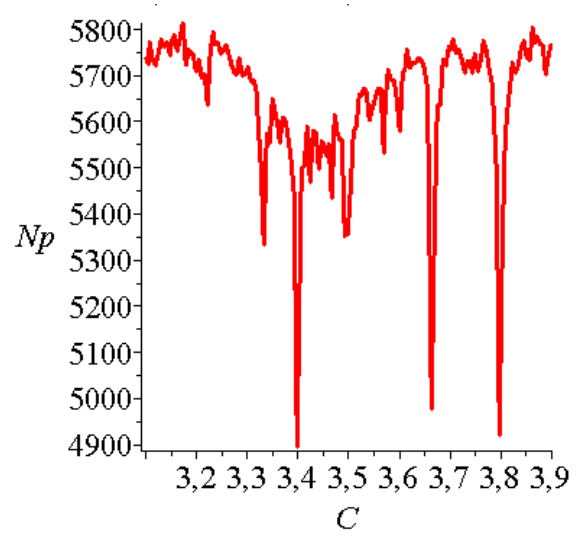

Fig. 3. Graph of dependence of the number of points on the image of the family of lines (1) on the values of $C$

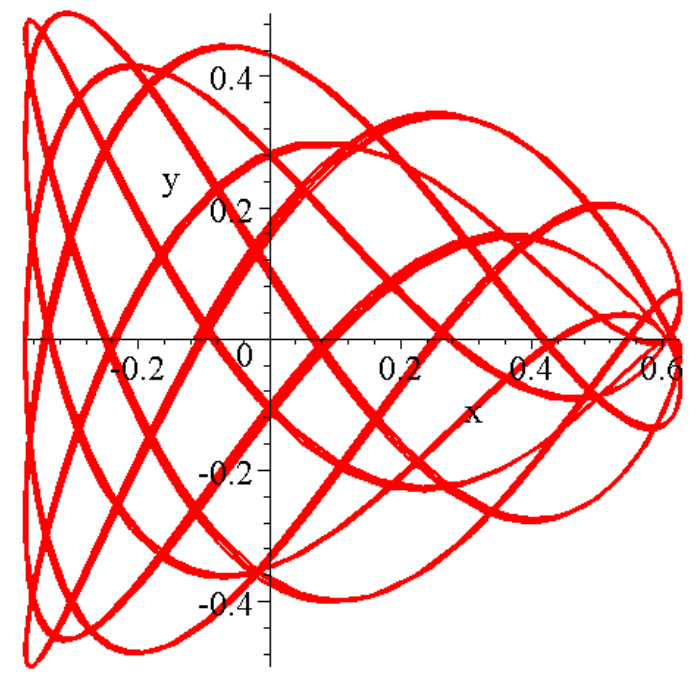

Fig. 4. Family element (1) at critical value of parameter $\mathrm{C}=3.3986$
Thus, the value of $\mathrm{C}$ was calculated, which will provide for the minimum saturation of the image of family of lines (1).

\section{2. Explanation of the idea of projection focusing}

Let us proceed to the explanation of notion of the idea about projection focusing [17].

Assume that in the Cartesian coordinate system Oxyt a parametric family of lines $\mathrm{L}$ is assigned, described by equations:

$$
x=x(t) ; y=y(t)
$$

whose projection $\mathrm{L}_{\mathrm{p}}$ onto the Oxy plane does not cross outside the rectangle:

$$
\mathrm{a}<\mathrm{x}<\mathrm{b} ; \mathrm{c}<\mathrm{y}<\mathrm{d} \text {. }
$$

Here $\mathrm{C}$ is the parameter that controls a spatial geometric shape of the family elements (i. e. a controlling parameter).

At the change of parameter $\mathrm{C}$ within the range

$\mathrm{u}<\mathrm{C}<\mathrm{v}$,

the saturation of the image of projection $L_{p}$ in the Oxy plane.

For the parametric family of lines L, described in parametric space $\{x, y, t\}$ by equations:

$$
x=x(t) ; y=y(t)
$$

it is necessary to compute such value of controlling parameter $\mathrm{C}$ (that changes within the range $\mathrm{u}<\mathrm{C}<\mathrm{v}$ ) at which saturation of the image in the Oxy plane of projection $\mathrm{L}_{\mathrm{p}}$ of family of lines is minimal. We shall denote the found value of parameter $\mathrm{S}$ as critical and designate by $\mathrm{C}_{c}$.

It is obvious that the critical value of parameter $\mathrm{C}_{c}$ is matched with the focus-line of family of projections $L_{p}$.

Definition. We shall denote as projection focusing a computing process for determining the critical value of parameter $\mathrm{C}_{c}$, which will enable finding the focus-line of projection family $\mathrm{L}_{\mathrm{p}}$.

Consider a family of lines, described by equations:

$$
\begin{aligned}
& x=\exp (\cos (C t))+5 \sin ^{2}(t+C) \\
& y=\exp (\sin (C t))+2,5 \cos (t-C),
\end{aligned}
$$

where parameter $\mathrm{C}$ changes within the range

$$
2.2<\mathrm{C}<4.5 \text {. }
$$

We compiled a program for the construction in space Oxyt of family elements (2) and their projections onto the Oxy plane depending on the values of parameter $\mathrm{C}$. Fig. 5 shows some of the elements of family (2). By using the program for determining the critical value of parameter, we compute $\mathrm{C}=3$. Respective focus- curve is shown in Fig. 5 at $\mathrm{C}=3$.

Thus, we calculated the value $\mathrm{C}=3$ that will provide for the minimum saturation of image in the projection of family of lines (2). 

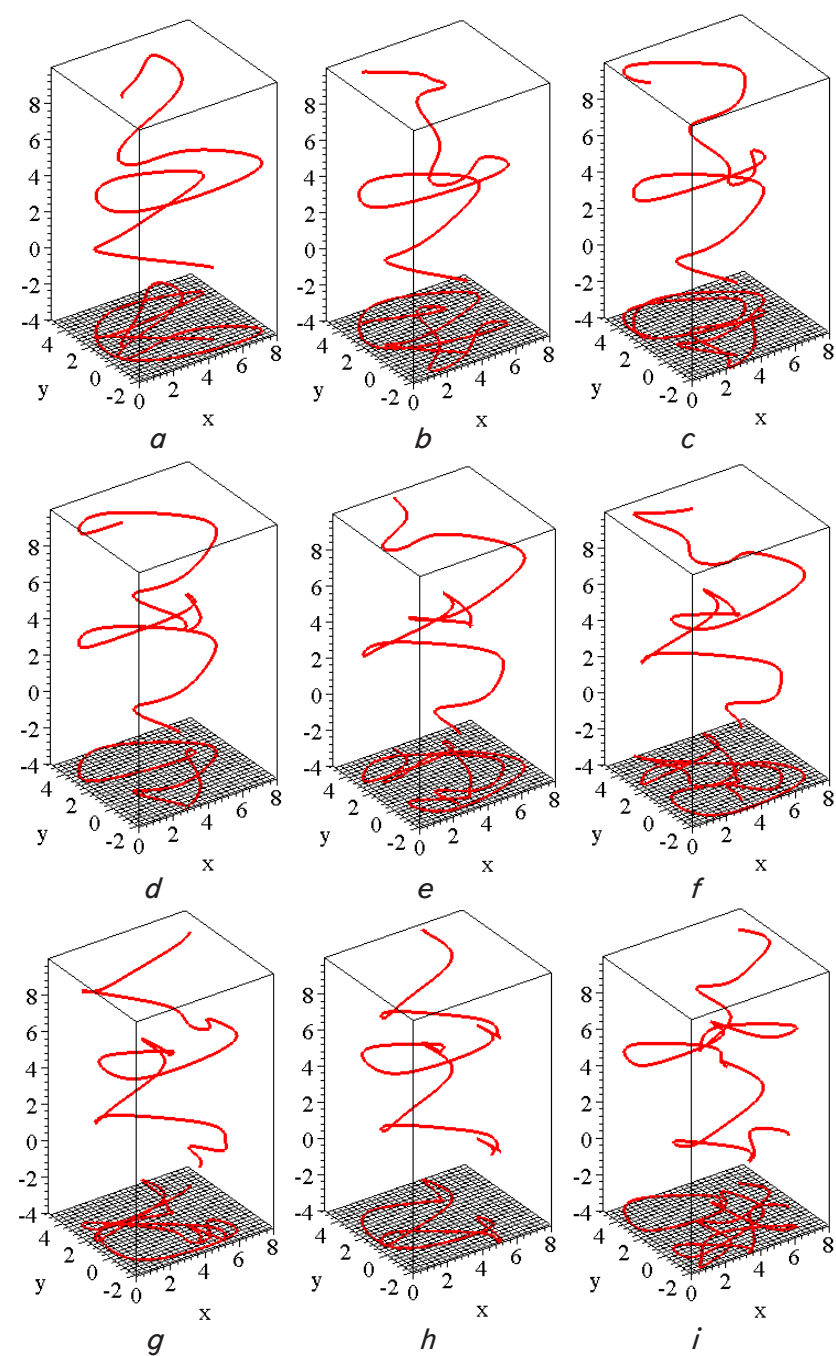

Fig. 5. Image of some elements of family (2) depending on the parameter $\mathrm{C}: a-$ at $\mathrm{C}=2.35 ; b-$ at $\mathrm{C}=2.66$;

$c-$ at $\mathrm{C}=2.85 ; d-$ at $\mathrm{C}=3$; $e-$ at $\mathrm{C}=3.27 ; f-$ at $\mathrm{C}=3.5$; $g-$ at $\mathrm{C}=3.77 ; h-$ at $\mathrm{C}=4 ; i-$ at $\mathrm{C}=4.46$

4. 3. Application of projection focusing for determining the non-chaotic oscillation trajectories of pendulum systems

Next, we shall consider how to apply the projection focusing to solve the problems on determining the non-chaotic oscillation trajectories of pendulum systems.

Let us enumerate conditions for the idealization of examples of the examined problems:

- parameters of the oscillatory system and initial conditions are assigned in conditional numerical units;

- oscillations of pendulums take place in the vertical plane;

- all elements of the system do not have thickness, are weightless and do not deform; supports in the nodes and air resistance in the course of oscillations are absent;

- an oscillatory system is conservative, that is, the reserve of mechanical energy in the process of oscillations remains constant (losses of energy are missing). We believe that the process of energy scattering proceeds slowly compared with the characteristic time scale in the system. This exerts a weak impact on the character of motion.

Example 1. Determining the non-chaotic oscillation trajectories of pendulum with a movable suspension point.
Mathematical pendulums with a movable suspension point are convenient models for testing the methods of exploring the oscillating processes. Of interest are the geometric shapes in the trajectories of moving along the plane (center) of load [18]. They illustrate the solutions of the corresponding differential equations that can be used by analogy in the problems similar in content [19].

Here is a graphic computerized method for choosing parameters' values to obtain the non-chaotic oscillation trajectories of the load in pendulums with a movable suspension point.

First, consider the case of oscillation of mathematical pendulum whose suspension point moves along the horizontal axis Ox. In this case, to describe the dynamics of motion, it is possible to apply [9] differential equation:

$$
\mathrm{L}\left(\frac{\mathrm{d}^{2}}{\mathrm{dt}^{2}} \mathrm{v}(\mathrm{t})\right)+\left(\frac{\mathrm{d}^{2}}{\mathrm{dt}^{2}} \mathrm{f}(\mathrm{t})\right) \cos (\mathrm{v}(\mathrm{t}))+\mathrm{g} \sin (\mathrm{v}(\mathrm{t}))=0 .
$$

The following designations are adopted in formula (3): $v(t)$ is the function of the magnitude change in the angle of pendulum deviation; $L$ is the length of the pendulum; $f(t)$ is the law of change in the position of pendulum's suspension point along the Ox axis; $g=9,81$.

We shall solve equation (3) by the Runge-Kutta numerical method with initial conditions:

$$
\mathrm{v}(0)=\mathrm{v}_{0} ; \mathrm{v}^{\prime}(0)=\mathrm{dv}_{0}
$$

In order to determine the values of parameters $\mathrm{v}_{0}$ and $\mathrm{dv}_{0}$, which would provide for the non-chaotic trajectory of pendulum load motion, we shall employ the method of projection focusing. For this purpose, by using the numerical method with the selected initial conditions and with a regard to function $\mathrm{f}(\mathrm{t})$, we solve equation (3). Next, we build the image of an integral curve in phase space $\{\mathrm{v}, \mathrm{dv}, \mathrm{t}\}$ depending on the value of "controlling" parameter; this may be, for example, the length of pendulum L. At arbitrary values $\mathrm{v}_{0}$ and $\mathrm{dv}_{0}$, there will form a "confused" integral curve in the phase space (Fig. 6, a). Let us project it onto phase plane $\{\mathrm{v}, \mathrm{dv}\}$, where we also observe a respective "confused" phase trajectory. In the case of change in the "controlling" parameter L, the character of phase trajectory must also change. At a certain critical value $\mathrm{L}=\mathrm{L}_{0}$, the character of phase trajectory will change at the qualitative level - it becomes the "natural" curve. In the phase plane, under the mode of computer animation, one may observe an optical-like effect of the image sharpening of confusion in the phase trajectories (Fig. 6, b). This process of finding the critical values of parameters is named a projection focusing.

Taking into account the critical value of $\mathrm{L}_{0}$ when solving differential equation (3) causes the emergence of point coordinates in plane $\{x, y\}$, which must be arranged along the non-chaotic trajectory.

For this purpose, the point coordinates along the load trajectory should be calculated according to formulas:

$$
\begin{aligned}
& \mathrm{x}(\mathrm{t})=\mathrm{L} \sin (\mathrm{v}(\mathrm{t}))+\mathrm{f}(\mathrm{t}) ; \\
& \mathrm{y}(\mathrm{t})=\mathrm{L} \cos (\mathrm{v}(\mathrm{t}))
\end{aligned}
$$

In this formula, $\mathrm{v}(\mathrm{t})$ denotes the approximated solution for differential equation (3). 

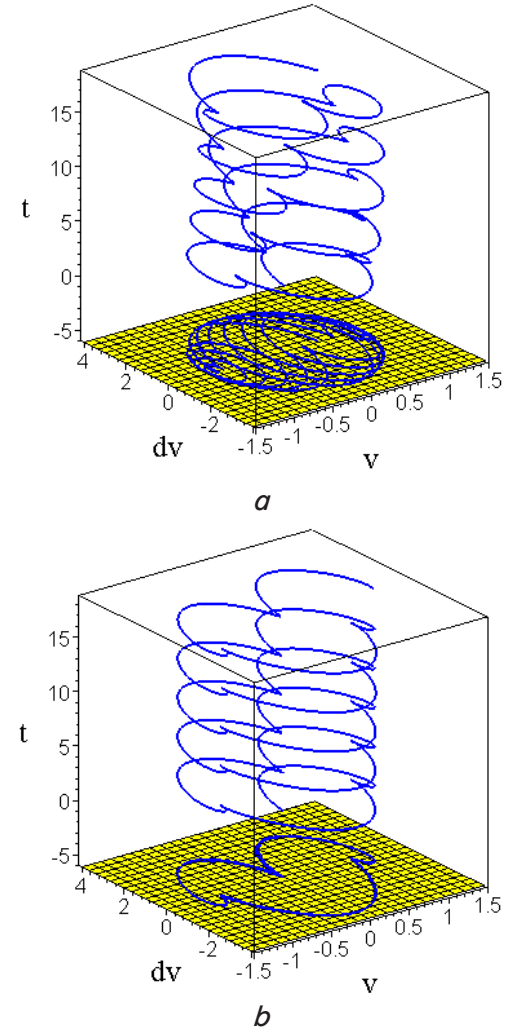

Fig. 6. Phase trajectories as projections of integral curves: $a$ - for an arbitrary value of "controlling" parameter L; $b-$ for a critical value of "controlling" parameter $L_{0}$

Here is an example of solving the equation (3) with the following conditions:

$$
\mathrm{v}_{0}=0 ; \mathrm{dv}_{0}=0 ; \mathrm{f}(\mathrm{t})=\sin (7 \mathrm{t}) / 2 \text {. }
$$

If one changes parameter $\mathrm{L}$, for example, within the range $2 \leq \mathrm{L} \leq 3$ at step $\mathrm{h}=0.2$, then we shall obtain a set of integral curves, one of which is shown in Fig. 7, $a$.

Critical value of the parameter will be obtained as a result of projection focusing at value $\mathrm{L}_{0}=2.456$, that corresponds to Fig. $6, b, 7, a$.

Fig. 7, $b$ shows example of geometric modeling of the pendulum oscillation process and construction of a non-chaotic trajectory. Fig. 8 shows other found variants of the nonchaotic trajectories.

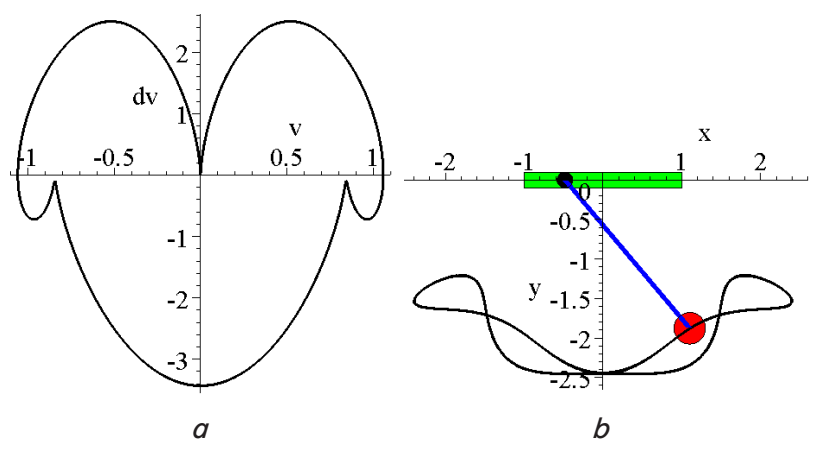

Fig. 7. Example of modeling the pendulum oscillations at parameters $v_{0}=0 ; d v_{0}=0 ; L=2.456 ; f(t)=\sin (7 t) / 2$ :

$a$ - phase trajectory; $b-$ a frame of the animation scheme of pendulum oscillation

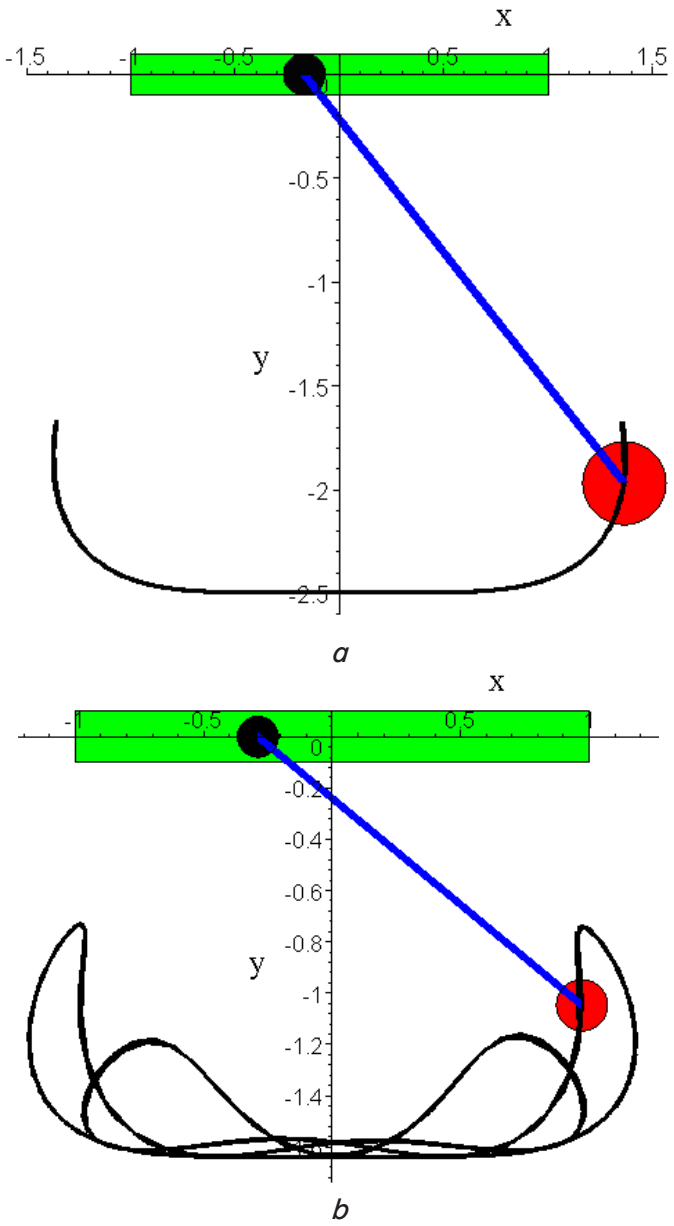

Fig. 8. Example of modeling the pendulum oscillation at parameters $\mathrm{v}_{0}=0 ; \mathrm{dv}_{0}=0 ; \mathrm{f}(\mathrm{t})=\sin (5 \mathrm{t}) / 2: a-$ at $\mathrm{L}=2.496333$; $b-$ at $\mathrm{L}=1.64$

Example 2. There are a significant number of publications, which address mathematical pendulums with a movable suspension point. Among them, a prominent place is taken by articles that tackle a variety of manifestations in the phenomenon of a certain type of pendulums - the Kapitza pendulums [10]. The most interesting is that the point of absolutely unstable equilibrium for a mathematical pendulum may turn to be a point of stable equilibrium for the Kapitza pendulum. In this case, they also consider the problems on parametric resonance when the lower state of equilibrium is not stable and the amplitude of small deviations of the pendulum increases over time. There are interesting effects when, at a large amplitude of forced oscillations, chaotic regimes may be realized in the system.

These studies would be advisable to supplement with a graphic visualization of the results of solving the equations that describe dynamics in the oscillations of pendulums with a movable suspension point. It is necessary to visualize the trajectories of load oscillations in order to detect the non-chaotic trajectories among them.

Let us consider the oscillations of mathematical pendulum whose suspension point moves along the vertical axis $\mathrm{Oy}$. To describe the dynamics of motion of the pendulum, we shall employ [9] differential equation:

$$
\mathrm{L}\left(\frac{\mathrm{d}^{2}}{\mathrm{dt}^{2}} \mathrm{v}(\mathrm{t})\right)+\left(\mathrm{g}+\mathrm{Aw} \mathrm{w}^{2} \cos (\mathrm{wt})\right) \sin (\mathrm{v}(\mathrm{t}))=0 .
$$


The following designations are adopted in formula (4): $\mathrm{v}(\mathrm{t})$ is the function of magnitude change in the angle of pendulum deviation; $\mathrm{L}$ is the length of the pendulum; $\cos (\mathrm{wt})$ is the law of change in the position of suspension point of the pendulum along the Oy axis; $\mathrm{A}$ is the amplitude of oscillations; $w$ is the frequency of oscillations; $g=9,81$.

We shall solve equation (4) by the Runge-Kutta numerical method with initial conditions:

$$
\mathrm{v}(0)=\mathrm{v}_{0} ; \mathrm{v}^{\prime}(0)=\mathrm{dv}_{0}
$$

To determine the values of parameters $\mathrm{A}$ and $\mathrm{w}$, which would provide for the non-chaotic trajectory of the pendulum load motion, we shall apply the method of projection focusing.

For this purpose, find the solution of equation (4) for $\mathrm{L}=0.1 ; \mathrm{w}=150$ and with initial conditions:

$\mathrm{v}_{0}=\pi / 20 ; \mathrm{dv}_{0}=0$.

Employing the method of projection focusing, we shall obtain critical values of oscillation amplitude A that ensure the non-chaotic load oscillations.

Taking into account the critical value of parameter A in the process of solving differential equation (4) will cause the emergence of point coordinates in plane $\{x, y\}$, which must be arranged along the non-chaotic trajectory.

For this purpose, coordinates of the points along the load trajectory should be calculated by formulas:

$$
\begin{aligned}
& \mathrm{x}(\mathrm{t})=\mathrm{L} \sin (\mathrm{v}(\mathrm{t})) ; \\
& \mathrm{y}(\mathrm{t})=\mathrm{L} \cos (\mathrm{v}(\mathrm{t}))+\mathrm{A} \cos (\mathrm{w} t) .
\end{aligned}
$$

In this formula, $\mathrm{v}(\mathrm{t})$ denotes the approximate solution of differential equation (4).

Fig. 9, $a-c$ shows examples of the geometric modeling of the Kapitza pendulum load trajectories for the found values of oscillation amplitude (frames of the animation scheme of the oscillation process are presented). Fig. 9, $d$ shows an example of the load chaotic oscillations for comparison.

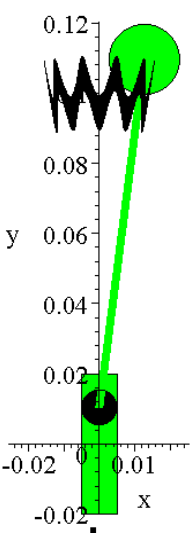

$a$

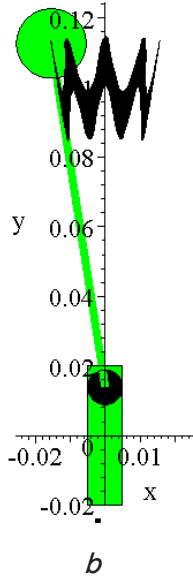

$b$

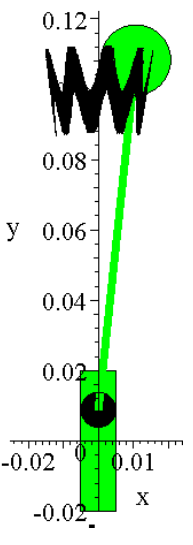

c

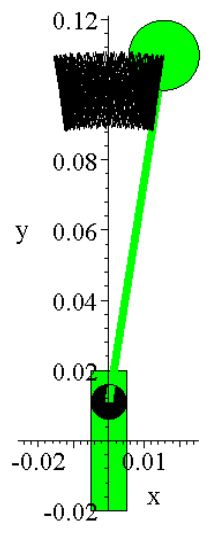

d
Fig. 9. Geometric modeling of the Kapitza pendulum trajectories: $a-$ for $\mathrm{A}=0.0105 ; b-$ for $\mathrm{A}=0.01469$; $c-$ for $\mathrm{A}=0.01245 ; d-$ for $\mathrm{A}=0.011$

Fig. 10 shows phase trajectories that match the oscillation cases of Fig. 9.
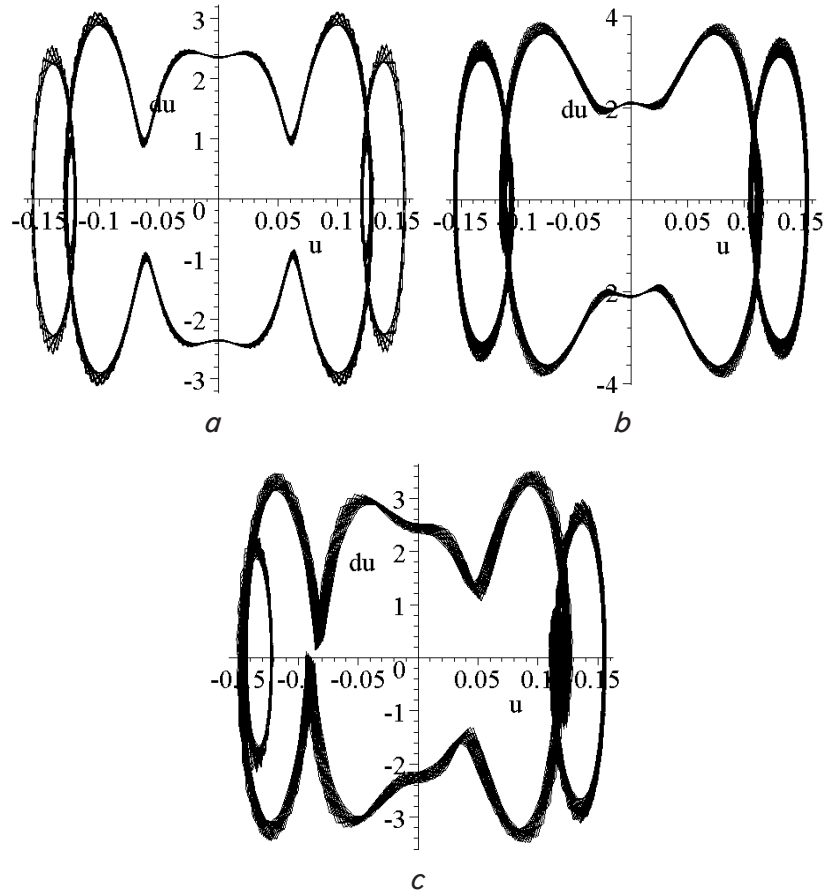

Fig. 10. Phase trajectories:

$a-$ for $\mathrm{A}=0.0105 ; b-$ for $\mathrm{A}=0.01469 ; c-$ for $\mathrm{A}=0.01245$

Thus, in order to obtain the non-chaotic trajectories of load oscillations for a pendulum with a movable suspension, the selection of parameters can be carried out based on the graphic method of projection focusing. These trajectories allow us to analyze the character of the obtained solutions.

Example 3. Determining the non-chaotic trajectories in pendulum oscillations of the Atwood machine's load.

In order to verify the laws of kinematics and dynamics, the Atwood machine is used, which consists of a vertical rod, atop of which is a light pullet mounted so that it is capable of rotating at little friction. A string runs over the pulley with the attached loads of identical masses M. Motion of this system of loads causes additional load of mass $\mathrm{M}$, which is added to one of the basic loads.

If the loads are identical, then potential energy of the system is not dependent on their height as the decrease in potential energy of one load leads to equivalent growth in the potential energy of another one. When loads are different, then the change in potential energy of the system is determined by the position of overload with mass $m$.

But there is another possibility to bring the specified system of loads out of equilibrium through altering its potential energy. For this purpose, one of the loads must be assigned with pendulum oscillations. Fig. 11 shows in the Cartesian coordinate system $\{\mathrm{x}, \mathrm{y}\}$ a schematic of the Atwood machine with a pendulum, where the sum of segments:

$$
|\mathrm{OA}|+|\mathrm{OB}|+|\mathrm{BC}|
$$

(that is the length of the string) must be constant. Then asymmetric weight gain due to the acceleration of pendulum will break initial equilibrium in the system and, through periodic motions of the pendulum, there will form a certain trajectory in the pendulum load displacement. For the applied problems, it is necessary to explore the specified variety of kinematic curves. 


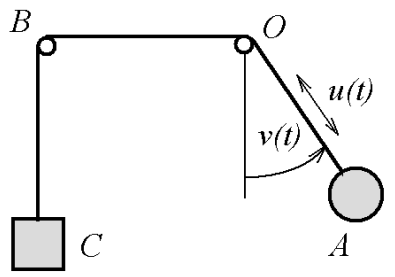

Fig. 11. Schematic of the Atwood machine with a pendulum

To describe the action of the Atwood machine with pendulum movements, they use [11] formulas for kinetic and potential energy:

$$
\begin{aligned}
& \mathrm{K}=0,5(1+\mathrm{w})\left(\frac{\partial \mathrm{u}}{\partial \mathrm{t}}\right)^{2}+0,5 \mathrm{u}^{2}\left(\frac{\partial \mathrm{v}}{\partial \mathrm{t}}\right)^{2} \\
& \mathrm{P}=(\mathrm{w}-\cos (\mathrm{v})) \mathrm{gu} .
\end{aligned}
$$

The following designations are adopted in expressions (5) (Fig. 11): $\mathrm{u}(\mathrm{t})$ is the function that describes pendulum extension; $\mathrm{v}(\mathrm{t})$ is the function of change in the angle of pendulum deviation; $w$ is the numerical value of the ratio of counter-weight load mass to the mass of pendulum load; $\mathrm{g}=9,81$.

By using the expressions for kinetic and potential energy, we build a system of second order Lagrange differential equations. Approximate solution of this system determines the sequence of points along the trajectory of pendulum load motion. By connecting these points, one may formulate an idea about the trajectory as a whole. However, at a random selection of the values of parameters, the resulting trajectory will take the form of a "non-technological" chaotic curve. Paper [12] examined the methods for ensuring the non-chaotic (including periodical) solutions through the choice of input parameters. The role of these parameters (except for w) was assigned to the values of functions $\mathrm{u}(\mathrm{t})$ and $\mathrm{v}(\mathrm{t})$ in the initial points of computations. However, these methods are based on the analytical transformations, are difficult to represent and are not universal.

Therefore, it is necessary to develop a graphic computerized method for choosing the parameters of non-chaotic trajectories of pendulum load oscillations in the Atwood machine.

By using formulas for the kinetic and potential energy (5), we obtain a Lagrangian in the form:

$$
\begin{aligned}
& \mathrm{L}=\frac{1}{2}(1+\mathrm{w})\left(\frac{\mathrm{d}}{\mathrm{dt}} \mathrm{u}(\mathrm{t})\right)^{2}+ \\
& +\frac{1}{2} \mathrm{u}^{2}(\mathrm{t})\left(\frac{\mathrm{d}}{\mathrm{dt}} \mathrm{v}(\mathrm{t})\right)^{2}-\mathrm{gu}(\mathrm{t})(\mathrm{w}-\cos (\mathrm{v}(\mathrm{t}))) .
\end{aligned}
$$

Based on the Lagrangian, we obtain a system of second order Lagrange differential equations:

$$
\begin{aligned}
& \left(\frac{\mathrm{d}^{2}}{\mathrm{dt}^{2}} \mathrm{u}(\mathrm{t})\right)+\left(\frac{\mathrm{d}^{2}}{\mathrm{dt}^{2}} \mathrm{u}(\mathrm{t})\right) \mathrm{w}- \\
& -\mathrm{u}(\mathrm{t})\left(\frac{\mathrm{d}}{\mathrm{dt}} \mathrm{v}(\mathrm{t})\right)^{2}+\mathrm{gw}-\mathrm{g} \cos (\mathrm{v}(\mathrm{t}))=0 \\
& \mathrm{u}(\mathrm{t})\left(2\left(\frac{\mathrm{d}}{\mathrm{dt}} \mathrm{v}(\mathrm{t})\right)\left(\frac{\mathrm{d}}{\mathrm{dt}} \mathrm{u}(\mathrm{t})\right)+\mathrm{u}(\mathrm{t})\left(\frac{\mathrm{d}^{2}}{\mathrm{dt}^{2}} \mathrm{v}(\mathrm{t})\right)+\mathrm{g} \sin (\mathrm{v}(\mathrm{t}))\right)=0
\end{aligned}
$$

A system of second order Lagrange equations with regard to the value of w will be solved by the Runge-Kutta numerical method with initial conditions:

- initial length of the string in pendulum part $\mathrm{u}(0)=\mathrm{u}_{0}$;

- initial speed in the change of string length $\mathrm{D}(\mathrm{u})(0)=$ $=\mathrm{Du}_{0}$

- initial angle of pendulum deviation from the vertical $\mathrm{v}(0)=\mathrm{v}_{0}$

- initial speed in the change of deviation angle $\mathrm{D}(\mathrm{v})(0)=$ $\mathrm{Dv}_{0}$.

In order to determine the values of these parameters, which would provide for the non-chaotic trajectory of pendulum load motion, we shall apply the method of projection focusing. For this particular problem, its essence is as follows: by using a numerical method with the selected initial conditions, we solve a system of differential equations (7) and build the image of integral curve in phase space $\{\mathrm{u}, \mathrm{Du}, \mathrm{t}\}$ depending on the value of "controlling" parameter w. In a general case, there will form a "confused" integral curve in the phase space (Fig. 12, $a$ ). Let us project it onto phase plane $\{\mathrm{u}, \mathrm{Du}\}$ where we also observe a "confused" phase trajectory. In case the "controlling" parameter w changes, the character of the phase trajectory must also change. At a certain critical value of $\mathrm{w}=\mathrm{w}_{0}$, the character of phase trajectory will change at the qualitative level - it becomes the "natural" curve. On the phase plane, a near-optical effect will be observed of the image sharpening in the confusion of phase trajectories (Fig. 12, b). This process of finding parameters' critical values is named the projection focusing.

Taking into account the critical value of parameter $\mathrm{w}$ when solving a system of differential equations (7) will cause the emergence of point coordinates on plane $\{x, y\}$, which must be arranged along the non-chaotic trajectory.

For this purpose, coordinates of the points along the load trajectory should be calculated by formulas:

$$
\begin{aligned}
& \mathrm{x}(\mathrm{t})=\mathrm{u}(\mathrm{t}) \sin (\mathrm{v}(\mathrm{t})) ; \\
& \mathrm{y}(\mathrm{t})=-\mathrm{u}(\mathrm{t}) \cos (\mathrm{v}(\mathrm{t})) .
\end{aligned}
$$

In this formula, $\mathrm{u}(\mathrm{t})$ and $\mathrm{v}(\mathrm{t})$ denote the approximate solution of the system of equations (7).

Here is an example of solving a system of equations (7) under conditions: $\mathrm{u}_{0}=1 ; \mathrm{v}_{0}=\pi / 2 ; \mathrm{Du}_{0}=0 ; \mathrm{Dv}_{0}=0$. If parameter w changes, for example, within $2 \leq \mathrm{w} \leq 2,5$ at step $\mathrm{h}=0.2$, we obtain a set of integral curves. One of such curves is shown in Fig. 12, $a$. Critical value of the parameter will be obtained as a result of projection focusing at value $\mathrm{w}_{0}=2.394$, which matches Fig. 12, $b$.

Fig. 13 shows an example of the geometric modeling of trajectory (Fig. 13, $a$ ) and action of the Atwood machine with a pendulum (Fig. 13, $b$ ). Fig. 13, $b$ shows a frame from the animation scheme of action of the Atwood machine with a pendulum. The pictured trajectory is advisable to compare to the results of paper [12], which were obtained by the means of analytical dependences.

Fig. 14 shows examples of geometric modeling the trajectory of the Atwood machine's pendulum load oscillations depending on some other values $\mathrm{w}$ of the ratio of counter-weight load mass to the mass of pendulum load.

Therefore, the selection of parameters for obtaining the non-chaotic trajectories of pendulum load oscillations in the Atwood machine can be carried out based on the graphic computerized method of projection focusing. 


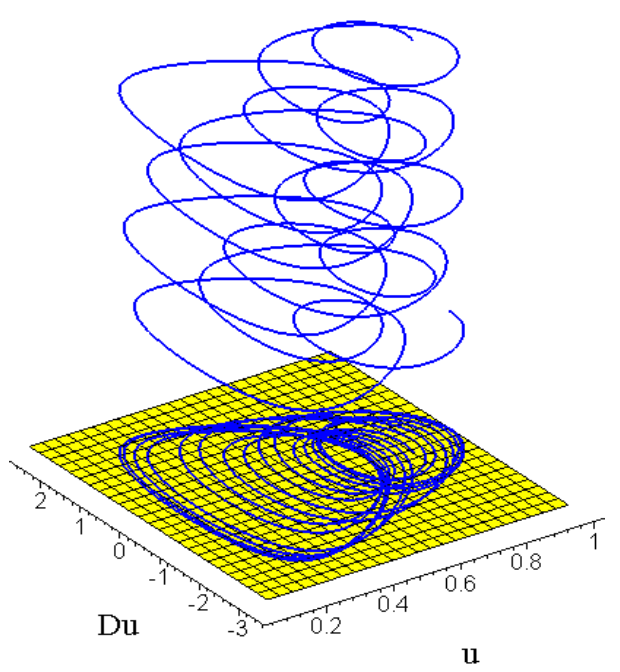

$a$

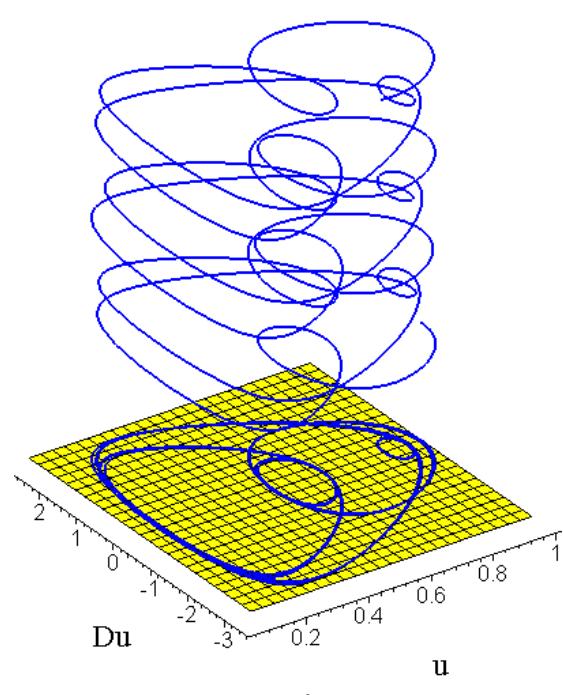

$b$

Fig. 12. Phase trajectories as projections of integral curves: $a-$ for an arbitrary value of the "controlling" parameter; $b$ - for the critical value of the "controlling" parameter

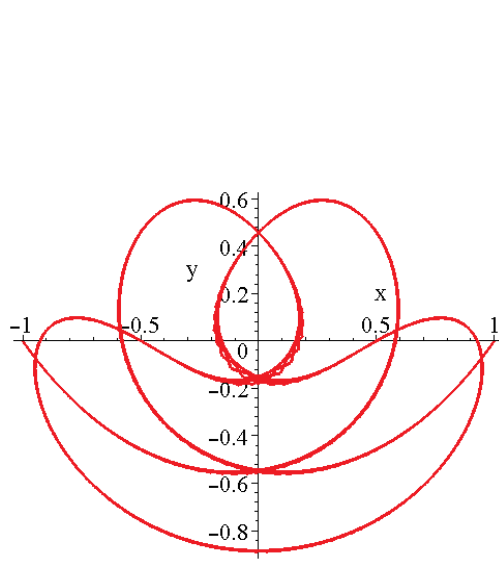

a

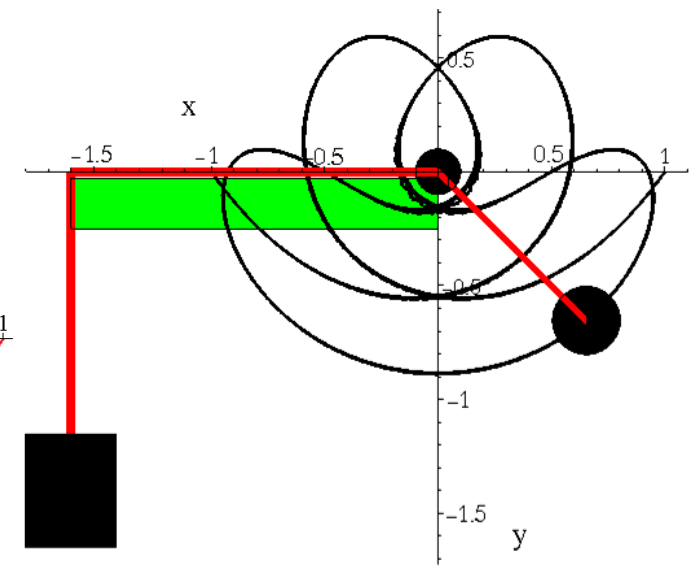

$b$

Fig. 13. Example of modeling the action of the Atwood machine under conditions $u_{0}=1$; $v_{0}=\pi / 2 ; \mathrm{Du}_{0}=0 ; \mathrm{Dv}_{0}=0 ; \mathrm{w}_{0}=2.394: a$ - pendulum load trajectory;

$b-a$ frame from the animation scheme of the Atwood machine action with a pendulum

5. Results of a computer graphic technology for determining the non-chaotic load oscillations in the pendulum mechanical conservative systems

As a result of the research conducted, we developed a technique for determining the non-chaotic trajectories of load oscillations for some varieties of pendulums using the graphic technology of projection focusing. For this purpose, we proposed to consider the phase trajectories of second order Lagrange differential equations of oscillations as the projections from the phase space onto the phase plane of integral curves of these equations. The influence of the value of controlling parameter on the image of phase trajectories was examined and we obtained the image of focus-line - a phase trajectory that is focused into the "regular" curve. The approximate solution to second order Lagrange differential equation with the selected value of controlling parameter will determine the non-chaotic trajectory of load displacement. Examples of applying the projection focusing are presented to solve the problems on determining the non-chaotic oscillations of pendulums with movable suspension points, as well as the calculation of non-chaotic trajectories for the pendulum motion of load in the Atwood machine.

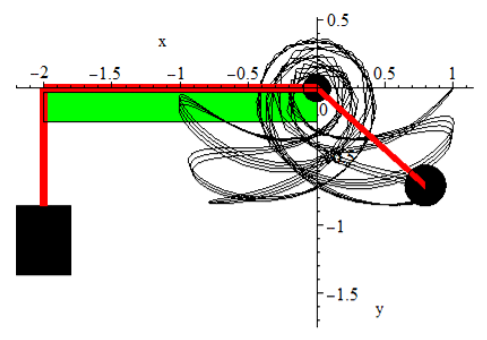

$a$

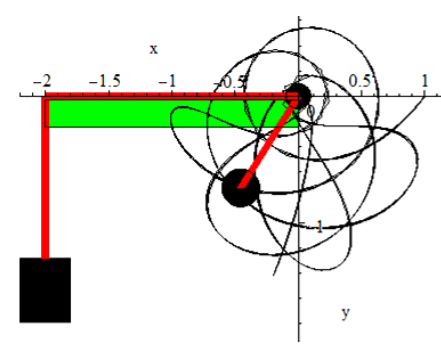

d

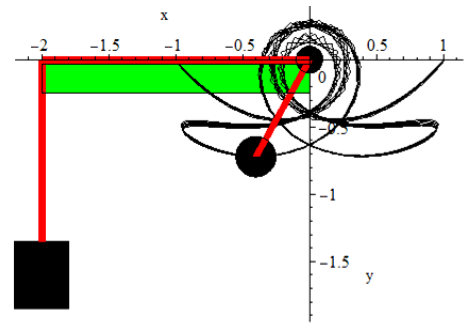

b

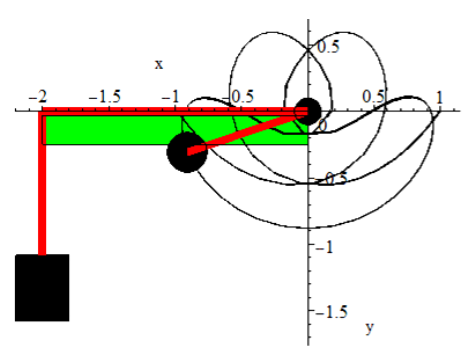

e

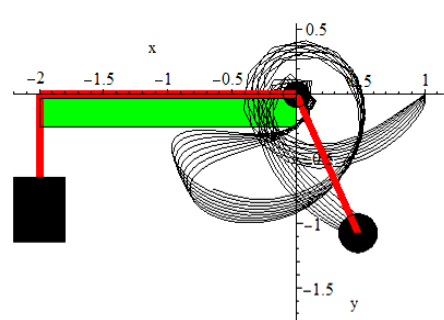

C

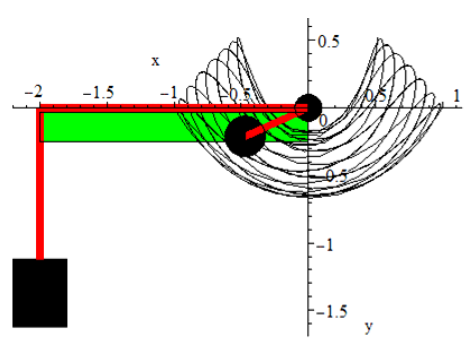

$f$

Fig. 14. Examples of the trajectory of the Atwood machine's pendulum oscillation depending on certain values w: $a-$ at $\mathrm{w}=5.5 ; b-$ at $\mathrm{w}=6.0 ; c-$ at $\mathrm{w}=4.7 ; d-$ at $\mathrm{w}=3.3 ; e-$ at $\mathrm{w}=2.4 ; f-$ at $\mathrm{w}=2.0$ 
The advantages of the devised method for determining the non-chaotic oscillation trajectories of loads in the varieties of pendulums by using graphic technology of projection focusing include the formalization of actions when searching for the periodic trajectories.

A shortcoming, however, is the fact that it is possible to apply the procedure developed mainly to conservative oscillatory systems.

The study might be used for pendulum mechanical oscillations, where the energy dissipation process proceeds slowly compared with the characteristic scales of time in the system that weakly affects the character of motion.

We plan to continue research into pendulum non-conservative oscillatory systems.

\section{Conclusions}

The developed computerized projection technique for simulating the oscillations of pendulum mechanical systems makes it possible to select the required values of parameters and initial conditions for initiating the oscillations that provide for the non-chaotic technological character of oscillation trajectory of elements in these systems.

We propose the notion of a focus-line of the parametric family of curves and the technique of projection focusing, which is based on this notion. This allows us to determine the critical values of controlling parameter in the family of curves, at which the image of elements of the family will take a minimum area (in pixel dimension).

We constructed integral curves in the phase space based on the numerical solution of second order Lagrange differential equations. These equations describe varieties of oscillations in the pendulum systems. The image was received of projection of the indicated integral curves onto the phase plane.

We present a procedure to determine the critical value of pendulum oscillations parameter by using the graphic notion of projection focusing of phase trajectories for the solutions of second order Lagrange differential equations.

The examples of determining the parameters of certain pendulums are given, which (the parameters) would provide for the non-chaotic trajectory of load oscillations.

\section{References}

1. Nedel'ko, N. S. Ispol'zovanie teorii katastrof k analizu povedeniya ehkonomicheskih sistem [Text] / N. S. Nedel'ko // Vestnik MGTU. - 2010. - Vol. 13, Issue 1. - P. 223-227.

2. Ostrejkovskij, V. A. Analiz ustojchivosti i upravlyaemosti dinamicheskih sistem metodami teorii katastrof [Text]: uch. pos. / V. A. Ostrejkovskij. - Moscow: Vyssh. shk., 2005. - 326 p.

3. Gavin, H. P. Generalized Coordinates, Lagrange's Equations, and Constraints [Text] / H. P. Gavin // Structural Dynamics. 2016. - P. 1-23.

4. Klimenko, A. A. Nelinejnaya dinamika pruzhinnogo mayatnika [Text] / A. A. Klimenko, Yu. V. Mihlin // Nelinejnaya mekhanika. - 2009. - Issue 27. - P. 51-65.

5. Malineckij, G. G. Nelinejnaya dinamika: podhody, rezul'taty, nadezhdy [Text] / G. G. Malineckij, A. B. Potapov, A. V. Podlazov. Moscow: URSS, 2006. - 280 p.

6. Kecik, K. Dynamics and control of an active pendulum system [Text] / K. Kecik // International Journal of Non-Linear Mechanics. - 2015. - Vol. 70. - P. 63-72. doi: 10.1016/j.ijnonlinmec.2014.11.028

7. Ding, F. Modeling and control of a novel narrow vehicle [Text] / F. Ding, J. Huang, Y. Wang, T. Matsuno, T. Fukuda, K. Sekiyama // 2010 IEEE International Conference on Robotics and Biomimetics. - 2010. doi: 10.1109/robio.2010.5723487

8. Butterworth, J. A. The effect of nonminimum-phase zero locations on the performance of feedforward model-inverse control techniques in discrete-time systems [Text] / J. A. Butterworth, L. Y. Pao, D. Y. Abramovitch // 2008 American Control Conference. - 2008. doi: 10.1109/acc.2008.4586900

9. Butikov, E. I. Stabilizaciya perevernutogo mayatnika (60 let mayatniku Kapicy) [Text] / E. I. Butikov // Komp’yuternye instrumenty v obrazovanii. - 2010. - Issue 5. - P. 39-51.

10. Shironosov, V. G. Rezonans v fizike, himii i biologii [Text] / V. G. Shironosov. - Izhevsk: Udmurtskij universitet, $2000 .-92$ p.

11. Yehia, H. M. On the integrability of the motion of a heavy particle on a tilted cone and the swinging Atwood machine [Text] / H. M. Yehia // Mechanics Research Communications. - 2006. - Vol.33, Issue 5. - P. 711-716. doi: 10.1016/j.mechrescom.2005.06.015

12. Tufillaro, N. B. Swinging Atwoods Mashine [Text] / N. B. Tufillaro, T. A. Abbott, D. J. Griffiths // American Journal Physics. 1984. - Vol. 52, Issue 10. - P. 895-903. doi: 10.1119/1.13791

13. Manzhaev, P. V. Issledovanie bol'shih kolebanij dvojnogo matematicheskogo mayatnika [Text] / P. V. Manzhaev, V. E. Levin // Trudy XVI Vserossijskoj nauchno-tekhnicheskoj konferencii "Nauka. Promyshlennost'. Oborona”. - Novosibirsk, 2015. - P. 526-530.

14. Semkiv, O. M. Hrafichnyy komp’yuternyy sposib vyznachennya nekhaotychnykh trayektoriy kolyvan’ mayatnykovykh system [Text] / O. M. Semkiv // Vestnyk Khar'kovskoho nats. avtomobyl'no-dorozhnoho unyversyteta. - 2016. - Issue 72. - P. 94-101.

15. Girsh, A. G. Kompleksnaya geometriya - evklidova i psevdoevklidova [Text] / A. G. Girsh. - Moscow: Maska, 2013. - 216 p.

16. Stepanenko, O. S. Rabota na PK v ofise [Text] / O. S. Stepanenko. - 3-e izd. - Moscow: Vil'yams, 2006. - 768 p.

17. Kutsenko, L. M. Doslidzhennya initsiyuvannya rukhu vizka za dopomohoyu kolyvannya 2d-pruzhynnoho mayatnyka [Text] / L. M. Kutsenko, O. M. Semkiv // Suchasni problemy modelyuvannya. - 2016. - Issue 6. - P. 71-76.

18. Vishenkova, E. A. K dinamike dvojnogo mayatnika s gorizontal'no vibriruyushchej tochkoj podvesa [Text] / E. A. Vishenkova, O. V. Holostova // Vestnik Udmurtskogo universiteta. Matematika. Mekhanika. - 2012. - Issue 2. - P. 114-129.

19. Nalavade, M. R. Balancing Double Inverted Pendulum on A cart by Linearization Technique [Text] / M. R. Nalavade, M. J. Bhagat, V. V. Patil // International Journal of Recent Technology and Engineering (IJRTE). - 2014. - Vol. 3, Issue 1. - P. $153-157$. 